\title{
Loucura, Expressão e Abstração: A Tensa Relação entre Nise da Silveira e Mário Pedrosa no Engenho de Dentro
}

\author{
Tania Rivera ${ }^{1}$
}

Resumo: O artigo analisa as concepções da psiquiatra Nise da Silveira e as contrapõe às formulações do crítico Mário Pedrosa, para propor uma reflexão aprofundada sobre o papel do ateliê de pintura do Centro Psiquiátrico Nacional na articulação entre expressão subjetiva, rigor geométrico e comunicação com o outro que constrói as bases da produção Neoconcreta.

Palavras-chaves: Expressão, Loucura, Arte Contemporânea Brasileira

\section{Madness, Expression and Abstraction: The Tense Relationship between Nise da Silveira and Mário Pedrosa at Engenho de Dentro}

ABSTRACT: This paper analyzes the conceptions of the psychiatrist Nise da Silveira and opposes them to the formulations of the critic Mário Pedrosa, in order to propose an in-depth reflection about the role of National Psychiatric Center's painting studio in the articulation between subjective expression, geometric rigor and communication with others that builds the foundations of Neoconcrete production.

1 É ensaísta, psicanalista e Professora Titular do Departamento de Arte e da Pós-Graduação em Estudos Contemporâneos das Artes da Universidade Federal Fluminense (UFF). Doutora em Psicologia pela Université Catholique de Louvain, Bélgica, realizou Pós-Doutorado em Linguagens Visuais na Escola de Belas-Artes da Universidade Federal do Rio de Janeiro. É autora dos livros Arte e Psicanálise (2002), Guimarães Rosa e a Psicanálise (2005) e Cinema, Imagem e Psicanálise (2008, todos por Jorge Zahar Editor), Hélio Oiticica e a Arquitetura do Sujeito (2012, Editora da UFF) e O Avesso do Imaginário. Arte Contemporânea e Psicanálise (2013, CosacNaify), que recebeu o prêmio Jabuti na categoria psicologia/psicanálise. Curadora de Lugares do Delírio (Museu de Arte do Rio, 2017 e SESC Pompeia, 2018), entre outras exposições.

E-mail: taniarivera@uol.com.br; ORCID: https://orcid.org/0000-0002-2951-0798; Instituição filial: Universidade Federal Fluminense 
Muitos pesquisadores indicam a relação do crítico Mário Pedrosa com o ateliê de pintura da psiquiatra Nise da Silveira no Centro Psiquiátrico Nacional como ponto de virada no direcionamento da vanguarda brasileira para a abstração geométrica, ou ressaltam seu papel para o posterior surgimento do neoconcretismo. A socióloga Gláucia Villas-Boas chega a falar do ateliê como lugar de "conversão" de Pedrosa (VILLASBOAS, 2008, p. 198). Tal articulação carrega contudo uma tensão entre o ideário de Nise e a produção efetiva de seus clientes, de um lado, e as elaborações teóricas do crítico, de outro, tendo como pano de fundo a complexa relação entre arte e loucura que vinha tomando forma na Europa desde a década de 1920.

Há entre a psiquiatra e o crítico um desacordo fundamental a respeito das relações entre as noções de expressão e geometria, como detalharemos abaixo. O dispositivo do ateliê de pintura coordenado por Nise da Silveira era marcado pela busca da expressão pura e direta, contrário à adoção prévia de qualquer regra formal ou "influência”. As obras nele produzidas - pelo menos a maioria daquelas foram consideradas "obras" e mostradas em exposições - são muito variadas, mas podemos considerá-las grosso modo, em sua maioria, como próximas dos valores formais expressionistas, em figurações deformadas ou estilizadas. Apesar de se aproximarem eventualmente da abstração informal e de composições geométricas - especialmente com Carlos Pertuis e Arthur Amora, nos primeiros anos - e do olhar de Pedrosa já destacar elementos nãofigurativos em texto sobre a primeira exposicão da produção do ateliê, realizada em 1947 (PEDROSA, 2015, p. 60) elas estão longe de caracterizar a produção do Engenho de Dentro como próxima da abstração geométrica que se afirmará na vanguarda brasileira nos anos 1950. De fato, estão muito distantes das obras que os artistas Mavignier e Palatnik, notadamente, começarão a produzir sob o impacto do contato com o ateliê e da influência de Pedrosa sobre eles. Vincular ambas é até mesmo surpreendente, na medida em que o ideário concretista negava os valores subjetivistas a ponto de fazer os artistas paulistas se posicionarem no Manifesto Ruptura de 1952 contra o "naturalismo errado" dos loucos (CORDEIRO et al., 2014, p. 168).

Este artigo busca apresentar em detalhes as tensões entre as concepções de Silveira e de Pedrosa, para chegar ao ponto em que convergem para embaralhar as dicotomias, então hegemônicas, entre os pares razão/forma/comunicação e desrazão/deformação/autismo, para conformar uma nova articulação entre afeto, alteridade e forma que será a matriz do movimento neoconcreto e suas derivações. 
O gesto de Nise da Silveira ao criar em 1946 os ateliês de terapia ocupacional do Centro Psiquiátrico Nacional no Rio de Janeiro articula-se de saída como precursor periférico do movimento antimanicomial que apenas na década de 1960 começará a impulsionar a demanda por serviços humanizados em regime aberto e ênfase na socialização dos pacientes. A psiquiatra recusa-se a aplicar em doentes os métodos convulsivantes então em voga, ao retornar do autoexílio que se seguira ao período na prisão por suas convicções políticas durante a Ditadura Vargas, e por isso é convidada a dirigir a Terapêutica Ocupacional, vista pela instituição como uma seção sem importância. Nise abre então oficinas de costura e encadernação, e em seguida põe em atividade o ateliê de pintura, em setembro de 1946, contando com a presença e o entusiasmo do jovem artista Almir Mavignier, que era funcionário do Hospital.

Logo a Seção de Terapia Ocupacional configura-se como um lugar diferenciado na instituição, caracterizado pelo acolhimento e respeito pelos internos. Ela estava em consonância com as primeiras experiências de abertura institucional por parte de psiquiatras europeus durante a Segunda Guerra, apesar de a psiquiatra provavelmente não ter tido acesso a informações detalhadas sobre elas nos seus primeiros anos de prática no ateliê.

Em livro de 1981 que apresenta uma síntese de sua trajetória, Silveira diz que seu interesse maior, desde cedo, era o de "penetrar, pouco que fosse, no mundo interno do esquizofrênico", que seria retratado em seus desenhos e pinturas (SILVEIRA, 1981, p. 11). Diante dessa produção, ela teria se surpreendido ao se deparar com "a existência de uma pulsão configuradora de imagens sobrevivendo mesmo quando a personalidade estava desagregada" (Ibid., p. 13). Logo ela se convenceria da "surpreendente eficácia da expressão plástica como verdadeira modalidade de psicoterapia" (Ibidem).

A pintura recebia dela especial atenção, pois "pintar seria agir", consistindo em "um método de ação adequado para defesa contra a inundação pelos conteúdos do inconsciente" (Ibidem). A visão da psiquiatra estabelece, assim, um jogo entre expressão e defesa, ao mesmo tempo em que identifica nas formas trazidas pelos seus "clientes" - como ela propunha que fossem requalificados aqueles que o manicômio taxava de "pacientes" ou "internos" - mandalas e outros símbolos oriundos do "inconsciente coletivo". Fascinam-Ihe especialmente as diversas variantes 
de mandalas que, baseadas na quadratura do círculo, apresentam tendência ao agrupamento, à simetria e à disposição ordenada de elementos díspares em torno de um centro (que corresponderia ao Self), segundo Carl Jung, servindo assim de modelo privilegiado da potência de formas organizadoras, arquetípicas, que advém espontaneamente do inconsciente coletivo em caso de dissociação ou desorientação psíquica.

Antes que ela mergulhasse no estudo da simbologia segundo Jung, a base teórica de Nise para iniciar os ateliês incluía ideias fundamentais de Freud sobre a relatividade da distinção entre normal e patológico e a respeito da arte como elaboração de fantasias e transmissão destas a outrem, e, por essa via, como meio de retomada ou construção de realidade (SILVEIRA, 1996, p. 92-93). Outras fontes permanecem obscuras. A concepção de Arte Bruta proposta por Jean Dubuffet em 1945 é citada em segunda mão de um livro de Michel Thevoz publicado em 1973, e Nise não menciona que grau de conhecimento teria dela antes disso. Do psiquiatra e filósofo Karl Jaspers é trazida uma citação de 1953 que traz a ideia de expressão direta que, como veremos, consiste no núcleo do discurso da psiquiatra. Jaspers afirma que Van Gogh o atrai porque lhe parece que "uma íntima fonte da existência abre-se diante de nós por um instante, como se viesse de profundezas ocultas, revelando-se diretamente." (JASPERS apud SILVEIRA, 1981, p. 15)

Nise não cita um texto publicado em 1932 sobre Picasso, no qual considerava que a consciência corresponderia sempre à figuração da realidade e toda "arte não-objetiva" proviria do "íntimo" e testemunharia de um "afastamento do objeto empírico" (JUNG, 1985, p. 119-120). O suíço levava alguns de seus pacientes a representarem seu "íntimo", nomeando tal prática como um "método de expressão" terapêutico, com a finalidade de tornar acessíveis os conteúdos inconscientes e aproximálos da compreensão, na medida em que são de saída e sempre considerados "simbólicos (Ibidem). Nos quadros de neuróticos, haveria "sentimento" ou eles são "carregados de um sentido inconfundível", ainda que sejam abstratos; já os esquizofrênicos produziriam obras "que revelam imediatamente a sua ausência de sentimento". Nestas predomina a fragmentação e elas nos deixam "frios" ou têm "efeito assustador por causa de sua falta de consideração paradoxal, sentimentalmente perturbadora, horrível ou grotesca" para com o espectador. "Picasso pertence a este grupo", conclui Jung (Ibid., p. 121).

Raramente se viu tamanho preconceito contra a arte moderna ser traduzido em "compreensão psicológica." 
Apesar de "prescindir do espectador", há contudo simbolismo na arte do esquizofrênico, segundo Jung. Enquanto diante da obra do neurótico "pode-se adivinhar o que ele quer expressar", no caso do psicótico - e de Picasso - pode-se adivinhar "o que ele não consegue expressar" (Ibidem). Seja como for, a decifração dos símbolos é apanágio do médico, e a "expressão" do paciente parece mais calá-lo do que lhe conceder alguma voz, já que o intérprete tem o poder de "adivinhar" o sentido de cada imagem a partir de símbolos e mitos. Assim, Jung pode afirmar sem hesitação que a figura do arlequim, comum na obra picassiana, "é um velho Deus ctônico", além de considerar que no desenrolar da produção do artista estaria em jogo "a jornada para o Hades, a descida para o inconsciente". A fase azul é declinada pelo psiquiatra em especulacões desenfreadas como "Picasso começa a pintar os quadros ainda objetivos em azul, o azul da noite, do luar e da água, o azul-Tuat do mundo inferior do Egito. Ele morre e sua alma cavalga para o além."(Ibid., p. 122).

Cabe perguntar quem "se expressa", neste texto. Seja como for, Jung acredita que algum "símbolo aparecerá como última causa e sentido de toda essa decomposição" (Ibid., p. 123). O intérprete encontrará apesar de tudo um sentido, uma mandala salvadora ou uma esperançosa união de opostos, algum mito, alguma figura erudita que seja capaz de normalizar a representação e assim aplacar sua angústia frente aquilo que, na imagem, resiste e põe em xeque a linguagem. Isso não significa, porém, que o artista vanguardista/esquizofrênico possa, no fim, salvar-se de alguma maneira:

Sobre o futuro de Picasso prefiro não fazer profecias, pois essa aventura "interior" é perigosa, podendo a cada instante levar à paralisação ou a uma catastrófica explosão dos opostos conjugados em tensão. (Ibid., p. 124)

O importante livro do psiquiatra e crítico de arte alemão Hans Prinzhorn, Imaginária dos Doentes Mentais ${ }^{1}$ (1922), é rapidamente mencionado por Nise como "verdadeiramente extraordinário", mas não pode ser considerado uma influência para a concepção do ateliê, na medida em que apenas em 1972 foi traduzido para o inglês na edição referida pela psiquiatra.

Seminal para a relação entre arte e loucura que se declinará pelo resto do século, ele trazia uma seleção do conjunto de cerca de cinco mil obras 
garimpadas em hospícios de diversos países europeus para formar a famosa coleção do Museu da Clínica da Universidade de Heidelberg. Lançando sobre as obras o olhar do conhecedor de arte que acompanhava a produção da vanguarda de nomes como Klee, Kandinsky, Alfred Kubin e outros, Prinzhorn via nestes trabalhos a comprovação da existência de uma pulsão de conformação (Gestaltung) universal que legitimaria as experimentações não-naturalistas dos artistas expressionistas.

A esquizofrenia apresentaria de maneira particularmente explícita a Gestaltung e seu fundamento instintivo, a "necessidade de expressão universal” (PRINZHORN, 1984, p. 49). O léxico que a acompanha delineará o campo conceitual que marca a interseção entre arte e loucura pelo resto do século: suas balizas são a noção de expressão, seu posicionamento como "originária" e próxima da pulsão, da necessidade ou do instinto, e a consideração de que ela evidencia a presença integral e direta do autor em sua obra. "Os movimentos expressivos têm por característica concretizar o psíquico, de maneira que ele nos é dado em uma participação imediata" (Ibid., p. 66), pois estabelecem "a comunicação com outrem" (Ibid., p. 67). Desta formulação se perpetuará a noção de "expressão" a salientar o que haveria de radicalmente pessoal na obra, ou seja, aquilo que seria menos pautado por protocolos estabelecidos do que por emanações sensíveis do autor, além do caráter imediato da relação entre elementos da obra e o suposto "psiquismo" de seu autor, posto em "comunicação direta" de modo que eventualmente vem legitimaria narrativas que prescindem de enunciações do próprio autor, ou as coloca em segundo plano.

O ateliê de pintura do Engenho de Dentro instala-se em um contexto já informado, ainda que vagamente, por tal noção de expressão. Ela é declinada por Nise no sentido de uma clínica baseada na humanização, em propiciar um ambiente acolhedor e digno. A psiquiatra não adota protocolos já formulados pela psicologia e a psicanálise, como testes projetivos ou manejos terapêuticos nos quais a atividade plástica é utilizada para suscitar as associações do paciente, nem tampouco se alinha aos procedimentos das nascentes propostas de arteterapia, nem mesmo aquelas com base na teoria de Jung. Ela segue ao pé da letra a ideia deste da potência conformadora dos arquétipos e especialmente das virtudes autocurativas expressas na mandala, mas talvez também demonstre respeito pela concepção de arte como produção desinteressada, que não serve a outra coisa senão a ela mesma e em si 
mesma encontra sua função e suas virtudes. Conversas com Mavignier e Pedrosa eventualmente podem tê-la influenciado neste sentido.

Em seu primeiro texto sobre o ateliê, de 1949, Silveira ligava a frequência com que doentes mentais buscariam "expressão gráfica" ao fato de na doença o pensamento abstrato regredir ao concreto e passar a fluir em imagens, fazendo com que o indivíduo "muito naturalmente" se exprima reproduzindo-as. O cliente pode projetá-las "sem nenhum intento de comunicar-se com outrem, impulsionado por mera tendência fisiológica à exteriorização"(SILVEIRA, 1996, p. 95). Aqui a psiquiatra alinha-se à ideia de expressão direta e autística: "os desenhos nascem inteiros de um só jato, multiplicam-se em número espantoso e suas cores são quase sempre muito vivas". Mas ela logo ressalta o caráter elaborativo da arte, que partiria de tal expressão para chegar à elaboração de uma "linguagem emocional":

\begin{abstract}
Mas apenas o ego começa a lançar frágeis pontes para o mundo real, aos modelos interiores vêm juntar-se objetos do mundo exterior recordados ou vistos no presente, a produção diminui e faz-se trabalho mais demorado, o colorido se enriquece de nuanças. Esses sinais indicam que passos começam a ser dados no caminho de volta à realidade, desenho ou pintura estão se tornando linguagem emocional. A atividade artística poderá mesmo adquirir o sentido de um verdadeiro processo curativo (Ibidem).
\end{abstract}

Assim, a pintura estaria ligada a "processos de autocura" nos quais seria instrumento para "reorganizar a ordem interna e ao mesmo tempo reconstruir a realidade" (SILVEIRA, 2000, p. 48). Posteriormente, no texto de 1981 já mencionado, ela afirma que sua "psiquiatria humanística" visaria

ajudar o doente a entender os conteúdos arcaicos invasores do consciente, originários dos estratos mais profundos da psique, não como realidade concreta segundo Ihe está acontecendo na situação psicótica, mas visa guiá-lo através da elaboração difícil e sofrida deste material na qualidade de linguagem simbólica (SILVEIRA, 1981, p. 13).

A interpretação simbólica em chave junguiana é, assim, tomada como parte da elaboração do material pelo paciente, e nesse sentido talvez não consista na selvagem "adivinhação" do terapeuta diante de um material que nada comunicaria, como dizia Jung. Ao contrário de seu mestre, Nise põe em primeiro lugar e acima de qualquer técnica a comunicação afetiva, a relação transferencial entre clientes e equipe do ateliê. Trata-se 
fundamentalmente da "emoção de lidar", afirma (SILVEIRA, 2009, p. 116).

A psiquiatra não explicita se suas interpretações simbólicas e mitológicas sobre determinadas obras chegavam a ser discutidas com os clientes e se geravam nestes alguma reação, ou se ao menos lhes eram comunicadas. As glosas que apresenta sobre clientes diversos estabelecem uma narrativa linear entrelaçando suas imagens a elementos biográficos/clínicos e a determinado mito. Não seria difícil, ao se dispor em séries as imagens produzidas por um cliente, "apreender o fio que thes dá sentido" (SILVEIRA, 1981, p. 37). Eventuais falas dos próprios pacientes são muito curtas e confirmam tais versões interpretativas, consistindo antes em citações poéticas ou anedóticas do que em elaborações terapêuticas. Mas talvez o mais importante seja que a psiquiatra considera seu olhar e sua elaboração interpretativa como a própria investigação do mundo esquizofrênico, e afirma que tal trabalho de pesquisa "é o próprio tratamento, porque se você consegue que o doente dê expressão, dê forma às emoções, isso já é uma função terapêutica" (SILVEIRA, 2009, p. 60).

Apesar da importância dada por Nise ao Inconsciente Coletivo de Jung com seus Arquétipos a se declinarem em narrativas mitológicas, a expressão não é simplesmente a exteriorização em jato de determinadas imagens que serviriam ao trabalho clínico, mas consiste na própria elaboração que se faz ali, entre ela e o cliente. Entre o psicótico e o monitor. Entre eu e outro - neste espaço intermediário no qual o afeto seria o "catalisador" fundamental.

Em fevereiro de 1947, Mavignier já organizava a primeira exposição do ateliê do Centro Psiquiátrico Nacional. Mário Pedrosa escreve sobre ela no Correio da Manhã, afirmando a universalidade do fenômeno artístico e ressaltando que estaria provado que a arte apazigua e pode "proporcionar aos fracos, aos doentes uma força de integração, de satisfação capaz até de curá-los ou salvá-los" (PEDROSA, 1947, s/p.). Ele começa então a acompanhar e frequentar o ateliê, levando outros artistas como Djanira, Décio Vitório e Geraldo de Barros, escritores como Murilo Mendes e críticos importantes como Léon Degand, diretor do recém inaugurado Museu de Arte Moderna de São Paulo, que organiza uma exposição nesta instituição em 1949. A produção cotidiana do ateliê estava portanto envolta não apenas por um ambiente de respeito, liberdade e cuidado terapêutico, como também por uma atmosfera de expectativa e 
experimentação artística que foi, sem dúvida, fundamental para o desenvolvimento das obras de seus artistas, e era sustentada no dia a dia por Mavignier, "monitor incomum" que, nas palavras de Pedrosa, carregava "uma fé ardente e romântica" na ideia de que "dentro da câmara escura daquele esquizofrênico havia um gênio" (PEDROSA, 1994, p. 9).

Nise de alguma maneira compartilhava esta "fé" na capacidade de seus clientes, mas a declina clinicamente, como pulsão configuradora de imagens tendendo à organização psíquica. Nisso a influência de Jung é certeira: trata-se de equacionar a abstração e a quebra do espaço representativo à desorganização e ao caos afetivo, e de valorizar como organizadoras as formas simbólicas (especialmente mandalas) e as composições figurativas. Seguindo este parâmetro, a psiquiatra afirma que as primeiras obras de Fernando Diniz eram caóticas e retratavam seu "mundo interno esquizofrênico". Aos poucos ele vai trabalhando o espaço representativo da casa - a morada que ele nunca havia tido em criança, sendo filho de uma costureira humilde que frequentava as casas abastadas de suas patroas. Ele vai recortando espaços domésticos em suas pinturas e fica muito feliz, segundo Nise, ao desenhar assoalhos que organizam o espaço segundo as regras da perspectiva linear, introduzindo neles elementos destoantes que trazem ritmo às composições, até que ele logra realizar um quadro no qual "cada coisa está no lugar esperado", diz Nise.

Após ter ordenado sua morada e portanto seu "ego" (SILVEIRA, 1981, p. 48), sua mãe morre e ele se desorganiza, voltando "a mergulhar no espaço escuro" e em "garatujas caóticas", nas palavras de Nise (Ibid., p. 69). Uma de tais "garatujas" parece-me contudo particularmente forte e bela como composição abstrata informal, trazendo a própria potência do traço tornado-se cor e textura mais ao centro da tela, e mostrando-se linhas retas ou curvas a partir em todas as direções em sua periferia.

Mencionando um livro de Wilhelm Worringer também estudado por Jung, Silveira pensa que a abstração estaria ligada à introversão da libido e corresponderia a uma "despotencialização" dos objetos, além de envolver uma precondição indesejável, se não patológica. Nos esquizofrênicos isso corresponderia à desarticulação da "linguagem proposicional", em seguida à qual poderia se afirmar "uma outra linguagem", uma "linguagem direta, força psíquica carregada de paixão e de angústia", e liberta de qualquer convenção (Worringer, 1953, p. 19). A este título Silveira valoriza algumas imagens abstratas informais de seus clientes, entendendo-as como próximas das Improvisações de Kandinsky. Mas suas expectativas terapêuticas estarão sempre direcionadas para o surgimento 
de composições figurativas, entendidas como uma conquista porque refletiriam a ordenação subjetiva do cliente. Ela reconhece no "geometrismo", contudo, a presença de "esforços instintivos para apaziguar tumultos emocionais e busca de refúgio em construções estáveis" (SILVEIRA, 1981, p. 25).

Nise ignora em seus textos obras como a de Arthur Amora, que frequentou o ateliê entre 1949 e 1951. Ele teria chegado desejando pintar, mas afirmava não saber desenhar. Mavignier lhe propõe então buscar um "motivo" que lhe interessasse, e ele descobre uma caixa de dominós. Copia-os e depois desconecta seus quadrados pretos de modo a formar curvas e interessantes dinâmicas, sempre em fundo branco. Dava a suas composições títulos de peças musicais clássicas - e esse não é o único motivo que nos faz desconfiar que estava a par da aproximação dos valores defendidos pelo ideário da arte abstrata com a música, tendo talvez ouvido comentários neste sentido de Mavignier, Pedrosa ou outro frequentador do Engenho de Dentro. Tenha ou não discutido ou presenciado diretamente discussões acerca de questões de composição, ritmo e forma, Amora mostra-se inegavelmente impregnado de tais questões em suas obras, apesar de Mavignier afirmar que seu geometrismo seria "consequente e livre de influências estrangeiras." (MAVIGNER, 2000, p. 164).

É pouco provável que Mavignier e Pedrosa jamais tenham conversado com Nise a respeito de tais composições geométricas. É tanto mais significativo, portanto, que a psiquiatra não mencione o crítico ou busque em seus textos elementos para essa discussão. Ela prefere citar Roberto Pontual e sua definição da Geometria Sensível como junção entre elementos como, de um lado, "cálculo, frieza, determinação, rigor, exercício da razão" e, de outro, "imprevisibilidade, animação, alternância, indeterminação, prática intuitiva". A arte do Engenho de Dentro permitiria, como uma lente de aumento, que se detectem "as interligações subterrâneas compensadoras" entre os dois aparentes polos opostos, diz Nise um tanto rapidamente (SILVEIRA, 1981, p. 31). Seguindo sua trilha, podemos dizer que ali talvez a esquizofrenia tenha tomado o lugar do elo perdido entre rigor geométrico e subjetividade, encarnando a articulação entre afeto e forma tão sonhada por artistas e críticos - e sobretudo, na arte brasileira, por Mário Pedrosa.

Ao ignorar as contribuiç̧ões de Pedrosa, o texto de Nise confirma de maneira patente o descompasso, ou melhor, a tensão que marcava a 
produção do ateliê, ao menos em seus primeiros anos, enquanto Mavignier ali trabalhava. E tal tensão sem dúvida acompanhou a escrita da tese de Pedrosa, Da Natureza Afetiva da Forma na Obra de Arte, que ele elaborava enquanto frequentava o Engenho de Dentro.

Boa parte do texto consiste em um libelo contra a leitura simbólica de obras de arte, a ideia de projeção e as referências subjetivistas, e na defesa de outra maneira de articular emoção e forma, seguindo a ideia que já se encontrava em texto de Naum Gabo de 1937: "A força emocional de toda forma absoluta é imediatamente irresistível e universal" (GABO Apud PEDROSA, 1995, p. 170). Pedrosa apoia-se firmemente na teoria da Gestalt para defender a primazia da forma na obra de arte como inerente e dada nela mesma, ao se constituir em campo perceptivo no qual estão incluídos de imediato o autor e o espectador. Para articulá-la ao afeto, dotando-a de qualidades emotivas nuanceadas, adere mais particularmente à ideia de Gestalt fisionômica que encontra em texto de Kurt Kofka de 1940, segundo a qual o modelo de boa forma é a fisionomia humana global, que o bebê muito cedo privilegia sobre qualquer elemento perceptivo (KOFKA, 1940). A fisionomia é imediata e globalmente captada por sua força expressiva como afeição, alegria ou tristeza, angústia etc., dando-se como comunicação afetiva nuanceada. Ela permite, assim, que se feche a equação entre Gestalt e expressão: "A unidade do todo não é senão a da expressão" (PEDROSA, 1995, p. 166), diz Pedrosa, para acrescentar ainda, recorrendo à síntese espaçotemporal que define a própria forma segundo esta concepção, que "a expressão vem antes de percebermos as coisas" (Ibid., 167).

A arte ativaria tal dimensão primeira da percepção ao dotar um objeto do poder fisionômico que compreendemos de imediato e que prescinde de qualquer narrativa ou associação. Aplicada ao objeto de arte, a Gestalt fisionômica permite portanto que Pedrosa chegue a uma síntese entre o objeto de arte em sua ipseidade e a recepção do mesmo na psicologia do espectador. E ao mesmo tempo, que atribua à obra o valor de comunicação e agenciamento de afetos entre pessoas.

Entre nós e o outro, o fenômeno artístico apresenta uma mediação incomparável o objeto de arte. Ele é dotado precisamente deste poder fisionômico que tão bem compreendemos, que o animal compreende, que a criança compreende, num rosto. A forma permite-nos comparar os aspectos sensíveis e fisionômicos das coisas e dos seres. (Ibid., p.160)

Kofka acentuava que um trabalho de arte revelaria "nosso lugar em um universo infinitamente maior do que nossos egos", mas não chegava a 
pensá-lo em termos de alteridade, como faria Maurice Merleau-Ponty desde 1945, na Fenomenologia da Percepção. A Gestalt fisionômica era para este uma referência fundamental e expandida, como fica claro quando afirma que "a coisa e o mundo se oferecem à comunicação perceptiva como um rosto familiar cuja expressão é logo compreendida", e que a arte busca "encontrar a fisionomia das coisas e dos rostos", como tentaria Cézanne ao pintar (MERLEAU-PONTY, 2011, p. 432). E portanto, já que a expressão é um modo de presença na forma, ou melhor, de presença-forma, ele pode chegar a afirmar que "no objeto cultural, eu sinto, sob um véu de anonimato, a presença próxima de outrem." (Ibid., p. 466)

É curioso que Pedrosa não cite o filósofo francês, de quem certamente leu ao menos "A Dúvida de Cézanne", também publicado em 1945. Apoiando-se na noção de expressão revista segundo a Gestalt fisionômica, este texto elabora uma fina discussão do tipo de interpretação psicanalítica então em voga, sem deixar de examinar a suposta "esquizoidia" do pintor francês. As convergências de interesse e da base teórica de Pedrosa com Merleau-Ponty eram portanto patentes, mas talvez incomodasse ao brasileiro a aderência deste, através de Cézanne, ao objetivo de abandonar o naturalismo acadêmico para melhor converter em objeto visível "a vibração das aparências que é o berço das coisas" (MERLEAU-PONTY, 2004, p. 2004). A arte moderna que serve de base para a fenomenologia do francês se libera das convenções para melhor mostrar como sujeito e mundo emergem no mesmo instante gestáltico, digamos, mas este mundo é aquele da percepção das coisas nelas mesmas, entendida como fenômeno irredutível e indissociável de suas "aparências". Já a busca de Pedrosa ia na direção de considerar que a arte devia "ignorar o aspecto familiar dos objetos", como queria o Suprematismo de Malevich, por exemplo, para expressar o "sentimento puro" ou a "sensação plástica" através da geometria, da cor e do ritmo (MALEVICH, 1996, p. 345).

As formulações de Merleau-Ponty não deixam de ressoar em sua tese, contudo, especialmente no gesto de pôr a arte entre "nós e o outro", declinando o universalismo defendido tanto por Gabo quanto por Kofka de maneira mais concreta, encarnada, e assim lançando o gérmen que desencadeará a atribuição de um lugar especial ao espectador pelas experiências neoconcretas, alguns anos mais tarde. 
Por ocasião do fechamento da exposição de 1947, Pedrosa apresenta como conferência seu importante "Arte, Necessidade Vital", que será publicado nos dias seguintes no Correio da Manhã. Uma importante referência neste texto é o psicólogo francês Henri Wallon, segundo o qual em momentos de decaída da consciência, como em Van Gogh, ou da inspiração que seria como uma "congestão" para Baudelaire, se desprenderiam de nós "partes que habitualmente esquecíamos fossem essencialmente nossas", e, no comentário de Pedrosa,

O corpo é então como uma espécie de campo exterior de sensações, as quais se dirigem e organizam independentemente de nós, como acontecendo a regular distância do nosso próprio eu. A consciência não é mais capaz de se opor a essas sensações, que acabam confundidas com a própria realidade ambiente (PEDROSA, 2015, p. 59-60).

Assim como em um desmaio ou síncope, nos estados gerados por uma perturbação mental a distinção entre eu e não-eu e sujeito e objeto se suspenderia, dando lugar a uma "difusão dos estados de consciência no espaço" (Ibidem). Apesar de seu "isolamento intransponível", os esquizofrênicos do ateliê de Nise da Silveira testemunhariam tal estado de fusionamento com os objetos do mundo. Assim, um dos expositores, mencionado no catálogo da exposição pela inicial D. e autor de uma obra intitulada Flausi-Flausi,

não é mais ele; está como disperso no ar, nas coisas; é um objeto dotado de antenas, um ente estranho, vivo, mas que não pertence mais a este nosso mundo; uma harpa, um triângulo sonoro; essas linhas coloridas que ele tece constroem uma espécie de nervura entre vegetal e animal, com a consistência de fibras úmidas como as de um tronco vivo de bananeira; é tudo uma trama, uma armação inédita para fins ainda indistintos; seria a estrutura inacabada de um dirigível irreal cuja cobertura já tivesse, no entanto, sido arrebatada pelos ventos do espaço. Informe ou descoordenado como se apresenta, tem tudo isso, contudo, uma qualidade musical esquisita, contraponto abstrato em que as linhas melódicas da personalidade dissociada se cruzam já não se coordenam, não se arrumam num conjunto acabado com princípio e fim (Ibid., p.60, grifos meus).

A anormalidade psíquica declina-se, neste trecho fulgurante, como despersonalização, em primeiro lugar, para logo encarnar um vibrante instrumento musical cuja música tudo decompõe em "linhas coloridas", em trama, em armação em germe, em movimento, sem significação definida. A estrutura é inacabada, tudo é informe e descoordenado e no entanto consegue a façanha de injetar nas linhas melódicas a própria "personalidade", disseminando-a. Em gesto singular, Pedrosa articula à 
dissociação esquizofrênica a estrutura complexa da trama de linhas coloridas. E embora pareça deste modo tocar o próprio gérmen do enodamento entre vontade construtiva e subjetividade destroçada, ele em seguida dá um passo atrás, cuidadoso, considerando que nesta, como nas demais "amostras embrionárias de arte" (Ibidem) ali apresentadas, faltaria

vontade realizadora, aquela terrível vontade quase inumana que vencia o caos interior em Van Gogh, impondo sua organização plástica e disciplinando suas forças explosivas, subordinando tudo à ordem cósmica final necessária à criação (Ibid., p. 61)

Ainda que sejam "amostras embrionárias", as obras do Engenho de Dentro confirmariam que a arte não é, do ponto de vista emotivo, "senão a linguagem das forças inconscientes que atuam dentro de nós" (Ibidem) e que não poderiam, segundo Marie Petrie, ser traduzidas pela palavra. Esta autora, que é uma das pioneiras da arteterapia na Inglaterra, é citada muito elogiosamente por Pedrosa como um dos "educadores" que usariam a arte como meio de harmonizar os complexos inconscientes e de buscar organizar as emoções humanas, defendendo o ensino da "gramática" artística a quem quiser aprendê-la, para que ela deixe de ser "o código secreto de uma elite" (PETRIE apud PEDROSA, 2015, p. 62). Portanto, na arte moderna - e Pedrosa cita o surrealismo em sua procura de um "modelo interior" em detrimento de um "modelo externo" - como em iniciativas terapêuticas,

\footnotetext{
A pintura fala uma nova linguagem: por ela se estabelecem novas possibilidades de contato com outros seres, contato esse que se dará precisamente nas regiões onde a palavra falada não pode penetrar, ou não pode ser chamada a intervir (PEDROSA, 2015, p. 62).
}

Tal linguagem liberta da mímesis e da significação - a linguagem geométrica que Mondrian, por exemplo, propõe com tanta força neste momento - é universal e propicia portanto, utopicamente, uma comunicação genuína e inclusiva entre os seres. Não se trata em absoluto da "linguagem simbólica" evocada por Nise da Silveira a partir de Jung, nem tampouco de um inconsciente coletivo como fundo comum a emergir do eu interior profundo. Aliás, é digno de nota que Pedrosa cite aqui Petrie e não Nise. A primeira, que era artista além de professora, defendia que o arteterapeuta se abstivesse de interpretar os trabalhos de crianças, para dar lugar apenas às associações dos próprios autores. 
A linguagem de que fala Pedrosa é jogo, dança de significantes, movimento, e é nela mesma que o crítico situa o inconsciente: "Que é a arte, afinal, do ponto de vista emotivo, senão a linguagem das forças inconscientes que atuam dentro de nós?" (Ibid., p. 61). Sublinhe-se aqui o termo forças, e a ausência do termo imagens. Sua fórmula demonstra, além de uma fina leitura da psicanálise através do automatismo surrealista, uma também aguda análise da própria produção surrealista, ressaltando a primazia da linguagem sobre as imagens e o eu. $O$ inconsciente são forças, não imagens, e tais forças se organizam como linguagem, sim, como trama, em ritmo como na tradição construtivista e neoplasticista - e é nesta organização que aparece o sujeito.

E por isso mesmo, no caso de enfermidade psíquica, o élan criativo não desaparece; ao contrário, pode até de intensificar, tornando-se mais "urgente e irreprimível", pois para Pedrosa a arte será então "o único veículo seguro e em que confiam, de comunicação com o exterior, de comunicação real, isto é, de alma para alma" (Ibid., p. 64). Se a arte pode ter efeitos sobre os doentes mentais, "curando-os ou alentando-os", ou atraindo-os a virem "de novo cá fora, no nosso mundo bruto e feio", graças a mensagens que fulguram como lampejos, isso não se deve em absoluto, portanto, à retomada da figuração entendida como religamento com a realidade empírica, mas sim ao fato de que "não há barreiras no mundo encantado das formas", ele não é de ninguém, sendo "comum a todos os homens indistintamente." (Ibid., p. 66)

Com "Arte, Necessidade Vital" não se trata assim, em absoluto, de simplesmente incluir o louco no rol de artistas possíveis, na medida da necessidade artística de todos, mas sim de ver na loucura revelar-se, como sob uma lupa, a arte como laço singular entre as pessoas, linguagem universal a ativar o campo ampliado no qual sujeito e objetos do mundo se equacionam e põem em jogo as oposições dentro/fora, sujeito/objeto e eu/outro.

A produção inicial do Engenho de Dentro, com a qual o crítico começava a ter contato, confirma assim neste momento, para ele, o quanto a arte deve ser tomada em um sentido mais amplo do que antes, alargando seu espectro para aquelas atividades lúdicas e desinteressadas nas quais se trata de "emprestar forma simbólica, mas forma aos conteúdos do eu profundo" e, mais radicalmente, de ver cada indivíduo como "uma organização plástica e formal em potência" (Ibid., 63). É importante sublinhar que cada indivíduo é aí tomado como tal organização em potência - e não como alguém capaz de deter tal potência. 
Essa ideia contradiz e ultrapassa o uso da expressão "forma simbólica" na citação anterior, que relega ao "eu profundo" seus supostos "conteúdos" e parece aludir aos arquétipos de Jung, apesar de Pedrosa não citá-lo. Mas para o crítico, como para Prinzhorn - que ele curiosamente não cita neste momento, mas logo buscará ler, como veremos -, a busca da forma é um trabalho cuja primazia deve ser afirmada sobre (e contra) a figura e a significação, e os símbolos são meros epifenômenos desta realização fundamental - formal, geométrica - que é nada menos que cada sujeito em potência, a se conformar na arte, em relação estreita com o mundo e o outro.

Em artigo publicado em março de 1950 com o título "Pintores de Arte Virgem", Pedrosa volta a aproxima a arte dos esquizofrênicos da caracterização geral da arte como "música". Devemos entrar em uma exposição como quem vai a um concerto, deixando de fora "os preconceitos, as ideias de realidade exterior e de imitação naturalista", diz ele. Esquecendo as tradicionais características dos objetos, podemos então nos sensibilizar "às alterações trazidas pelos artistas, na sua visão mais pura ou mais profunda, mais simples ou mais complexa, alucinada ou visionária." (PEDROSA, 1950, s./p.)

O que leva os criadores espontâneos do Engenho de Dentro a tal liberdade em relação às convenções representativas seria sua própria enfermidade, fazendo surgir "um novo mundo imaginário" que não se adequa aos moldes formais tradicionais. Ele convoca "novos esforços" para lhe dar "expressão plástica", e então "a forma se modifica e se enriquece. As habilidades aprendidas tendem a desaparecer para só ficar o dinamismo expressivo, o ritmo puro" (Ibidem). É muito interessante que o ritmo seja aí posto em primeiro plano, assim como nos Boogies Woogies de Mondrian, por exemplo, ainda que a figuração seja predominante nos trabalhos apresentados na exposição de 1949 a que ele se refere. Pedrosa convoca os desenhos de Raphael para desvendar como seu "segredo" o "fluido rítmico", a pulsar em manifestações desinteressadas que combinam jogo e ornamento. E analisa a atitude do artista ao criar como "expressão" maior desse jogo desinteressado:

Rafael desenha cantarolando ou em solilóquio monossilábico. O pincel ou a pena frequentemente é suspenso para ele fazer um gesto gratuito com o braço. Ora traspassa o pincel pelas costas de uma para outra mão, ora pinga um ponto no canto do cavalete, na ponta da mesa ao lado, no primeiro objeto ao alcance do braço. Essa fantasia se manifesta ainda nas mil maneiras com que põe sua assinatura, depois do trabalho realizado. (...) Sua linha é a projeção de uma mímica gratuita. Obedece a um 
ritmo misterioso que não nasce na tela nem se limita ao plano da composição. Vem de longe, como um seguimento do gesto do braço que desliza sobre o papel. É dotada por isso mesmo de uma gratuidade natural, que faz seu encanto. É afirmação pura. (Ibidem)

A expressão é aqui "afirmação pura" do sujeito na medida exata em que põe Raphael "fora de si", em gestos fora do padrão, gestos sem sentido, gestos que vêm "de longe". E Pedrosa com eles se encanta, mostrando que é no desinteresse, na falta de intenção de expressar algo, na contramão da própria língua e dos sentidos que se expressa a arte, afinal, "em pureza, em graça, harmonia, finura". Em sua "trama" palpita assim, apesar de fora de si - ou melhor, porque fora de si, justamente - "uma personalidade", uma "alma aflita por exprimir-se quando a linguagem verbal já não the serve mais de agente de comunicação com os homens." (Ibidem)

Se Raphael se auto-isola, como reconhece contudo Pedrosa, é na tentativa de conservar algum equilíbrio, e de modo vinculado a uma espécie de depuração do eu: a dissociação de seu mundo teria resguardado apenas o que há de mais "interior no seu eu frágil". Daí viriam a sobriedade de seus gestos, a economia de linhas e planos e a ordenação rítmica dos arabescos. "A forma", prossegue o crítico, abismado com a precisão de cada gesto do artista, "é para ele uma reação instintiva ao relâmpago das imagens na representação intuitiva". Descrevendo mais detalhadamente seu processo criador, Pedrosa afirma ainda que em primeiro lugar surgiria nele uma tensão, uma perturbação vinda "de fora", e que a ela Raphael reagiria bruscamente, "no esforço de transformar a percepção em imagem e forma" e assim retomar o equilíbrio. A progressão de um primeiro momento de expressão, direto e imagético, para um segundo momento no qual prevalece o ritmo e a forma, ecoa as ideias de Nise da Silveira já expostas, o que torna ainda mais eloquente o silêncio da psiquiatra a respeito das elaborações teóricas do crítico. Nise provavelmente quer evitar tratar do descompasso entre eles: enquanto para ela a etapa elaborativa corresponde a composições figurativas ou formas simbólicas, para o crítico se trata de forma e ritmo, despojados tanto de simbolismo e figuração quanto de conteúdos supostamente "internos".

Tal despojamento coincide com a "depuração" do eu que Pedrosa encontra em Raphael, e a chave da autenticidade expressiva é assim localizada por Pedrosa na dissociação psicótica, em contraste com o automatismo que serve à mera "projeção" da personalidade do artista nas propostas tachistas e expressionistas abstratas então em voga, nas quais 
"o pintor mescla suas afeições e sentimentos pessoais, seus desejos e faniquitos mais explícitos ao ato de realizar", como ele dirá em artigo de 1959 (PEDROSA, 2015, p. 336). Rechaçando o "individualismo aristocrático do autor" (Ibid., p. 344), os pacientes do Engenho de Dentro assumem o papel de arautos da alteridade que nos é constitutiva, e que a arte poria em prática de modo a convidar a laços íntimos com o outro, em conformacões estéticas que não deixam de ser políticas. Em vez de conjugar a forma à impessoalidade, à objetividade da obra, à razão, a vivência com esses "loucos" permite assim que Pedrosa a articule a uma noção de sujeito não-identitária, na qual a singularidade é alteritária e portanto implica uma comunicação direta com o contemplador. É então que "a obra de arte vive subjetivamente", na lapidar proposta de Pedrosa (PEDROSA, 2015, p. 176).

No texto "Forma e Personalidade", publicado como separata da revista Forma em 1951, Pedrosa argumentará com mais vagar a respeito destes pontos, dialogando com diversos autores. Apoiando-se em Roger Fry, ele começa por denunciar que a interpretação analítica de obras de arte e a explicação da arte em termos de realização de desejo ou sublimação deixariam de lado o fundamental da experiência artística. Para o crítico inglês, nesta estaria em jogo um substrato anterior a toda vivência individual, algo muito antigo, vindo de traços residuais inscritos "no espírito" pelas experiências emocionais primárias, sem conexão contudo com suas "vivências particularizadas" (FRY Apud PEDROSA, 2015, p. 130). Apontando de passagem a analogia com esta proposta, Pedrosa traz neste ponto, em nota de rodapé, longa citação de Jung a respeito dos arquétipos e do inconsciente coletivo, sem contudo comentá-la.

A deferência ao pensamento junguiano parece vir do reconhecimento de que a ideia de formas preexistentes a se conformarem de maneira independente das vivências individuais como uma força que tende à síntese, como vimos na mandala, pareceria em alguma medida ecoar a defesa da potência da boa forma em sua universalidade. Mas o prosseguimento do texto de Pedrosa critica e recusa com vigor a primazia dos símbolos, da leitura simbólica e das interpretações analíticas que tratam as obras como se fossem sonhos. Ao fazer este tipo de análise, o psiquiatra estaria "no exercício admirável de sua clínica", mas não estaria tratando do problema da criação nem investigando o campo da estética propriamente dito (PEDROSA, 2015, p. 133). 
No bojo desta argumentação, Pedrosa cita Prinzhorn na crítica à "maneira de ver puramente de conteúdo, analítica e interpretativa de símbolos" (PRINZHORN Apud PEDROSA, 2015, p. 133), justamente para acentuar que, apesar de podermos abordar uma obra de arte sob aspectos diversos, só vivenciamos sua "natureza intrínseca" quando a tomamos exclusivamente "como forma, sem fins externos". Na defesa dos "componentes supra-individuais da Forma" por Prinzhorn, Pedrosa encontra assim a confirmação de que "os motivos vitais do criador não são os do homem privado", e devem ser declinados como algo "mais geral, mais impessoal, mais essencial" (PEDROSA, 2015, p. 132). No entanto, deve-se reconhecer que as obras dos pacientes psiquiátricos serviram de pedra de toque para a defesa surrealista do homem privado como aquele a privilegiar o "modelo interior" sobre o modelo externo, ajudando assim a abrir o campo da arte para toda uma gama de producões naïfs marcadas pelo selo da subjetividade afirmada. Deve-se considerar que se os "sonhos e símbolos nada dizem sobre o valor autêntico da obra", como sentencia Pedrosa, no caso de tais produções eles fazem parte do próprio assunto das obras (Ibid., p. 135). O "subjetivismo inconsciente" tornou-se assim toda uma corrente da arte moderna, e no caso do surrealismo se erigia em supremo princípio, a contradizer os preceitos formalistas. Mas o brasileiro acredita que a oposição entre inspiração e forma ou subjetividade e objetividade teria sido superada pelo próprio líder do movimento surrealista, André Breton, sob a influência dos princípios da Gestalt. Em texto de 1941 no qual faz um balanço do Surrealismo, o francês liga o automatismo gráfico e verbal à realização da "unidade rítmica" que garantiria a não distinção entre "qualidades sensíveis" e "qualidades formais", e frisa que isso se daria sem prejuízo das "tensões individuais profundas que ele tem o mérito de manifestar e mesmo, dentro de certos limites, de resolver" (BRETON Apud PEDROSA, 2015, p. 137-138). Tal "unidade rítmica", longe de se opor ao subjetivo, confirmaria assim que "o automatismo é a única coisa que satisfaz igualmente ao espírito", conclui o surrealista (PEDROSA, 2015, p. 138).

Para Pedrosa, isso sela a superação final da querela entre realismo e não realismo - e sua argumentação é preciosa por mostrar um denso e singular entendimento da questão da realidade: "ninguém escapa à realidade, muito menos a alma sonora e sensível do artista, nem a realidade tem outro meio de se manifestar senão através da forma" (Ibidem). Está superada a caracterização do subjetivo como distante da realidade, e desfeita a equação loucura = modelo interior, e portanto não se trata de evocar uma "surrealidade" para chegar a esta síntese: basta a forma. Tampouco cabem os preceitos do realismo socialista, taxado pelo crítico trotskista de "naturalismo acadêmico da mais baixa espécie" e que 
não seria sequer digno de consideração, na medida em que "o conceito de realidade tem hoje outra profundeza, desde a revolução na psicologia trazida por Freud e os teóricos da estrutura." (Ibidem)

Pode parecer surpreendente que a psicanálise apareça em tal posição de destaque, e associada à teoria da Gestalt, logo após ter sua dimensão interpretativa totalmente descartada. Não se trata de incoerência, porém, mas sim de um dos momentos em que o crítico mostra a profundidade e consistência de suas leituras de Freud e da articulação crítica destas com o ideário surrealista - que também deve ser reconhecido como referência fundamental para seu pensamento, como mostra a citação de Breton que trouxemos acima.

Apenas em texto publicado em 1958 sobre arte e psicanálise emergirá uma das pontas desta reflexão subterrânea. É muito curioso e significativo o modo como Pedrosa nele introduz a psicanálise: ele ressalta que os psicanalistas insistem em apontar na arte a função de comunicar. Talvez tenham sido suas leituras de Freud a influência fundamental que já se fazia sentir desde a conferência de 1947 nas ideias de que a arte fomentaria novas formas de contato e de mediação entre nós e o outro, mais do que Merleau-Ponty. Seja como for, Pedrosa discorda do psicanalista, ao dizer que a comunicação em jogo na arte moderna não passaria pela identificação com o herói e pela catarse, como especula Freud em $A$ Interpretação dos Sonhos, (FREUD, 1996) mas sim por uma maior "participação", pela "resposta ativa" do público. Isso configuraria na arte nada menos que uma "nova ética" - e é para ela, justamente, que Freud nos teria aberto o caminho (PEDROSA, 2015, p. 331).

No texto de 1951 que vínhamos comentando, Pedrosa postula uma especial tendência dos pacientes psiquiátricos à Gestalt fisionômica.

(...) entre os adultos, os doentes mentais não precisam passar por experimentações de laboratório para perceber as coisas, as formas, sem indiferença, ou fisionomicamente. Eles não precisam ser induzidos a uma atitude emocional prévia para perceber a "cara" das coisas. Veem tudo simultaneamente por dentro e por fora. Daí é que tão espontaneamente, tão facilmente se deixam levar por uma atitude estética; e quando são dotados de talento plástico, realizam obras de causar admiração. (Ibid., p. 149. Grifos meus)

É muito interessante e original a ideia de que os esquizofrênicos teriam capacidade fisionômica excepcional, e a declinação de tal capacidade 
como possibilidade de ver simultaneamente por dentro e por fora, ultrapassando a barreira entre eles. Com ela, Pedrosa consegue a façanha de encontrar um ponto de articulação mais preciso entre a Gestalt e a loucura do que aquele da Gestaltung em Prinzhorn, e de fazer deste o modelo de subjetividade não restrito a seu "dentro", à suposta interioridade de um mundo próprio ou um "modelo interior". O eu do insano está fora - afinal, "eu é um outro", como já dizia Rimbaud falando das condições de base da poesia. Não é furtivo o uso da expressão "estar fora de si": ela afirma o descentramento do eu vivido em situações de crise e mantido em estados psicóticos assim como em situações de uso de drogas, entre outros modos culturais de alteração da consciência.

Em vez de embotados afetivamente, Pedrosa caracteriza os insanos, em seguida, como particularmente dotados de afeto, dessa "extrema afetividade expressiva na visão" que compartilhariam com "as crianças", "os selvagens primitivos" e "os artistas em geral" (Ibid., p. 145). Sua "necessidade primordial de expressão", Pedrosa a concebe como "a exteriorização do que na psique é essência irredutível, ou a ponte de comunicação do "eu" com outrem"(Ibid., p. 164-165). Algo na psique é intrinsecamente comunicação com o outro, e se a "doença mental" apresenta de maneira exacerbada tal necessidade, saem de cena o autismo e o isolamento - que foram a base da idealização do louco artista na Europa, desde os anos 1920, como representante da arte "pura" -, para dar lugar à figura do louco como encarnação da alteridade. A doença mental passa a ser, com Pedrosa, a condição na qual se revelariam e ativariam as condições da ligação primordial com o outro e com o objeto que estão habitualmente presentes nos artistas: relação direta, fisionômica, afetiva ao mesmo tempo que formal, espacial - e topológica, ao conjugar dentro e fora.

Apesar de se apoiar na Gestaltung de Prinzhorn, Pedrosa a declina de modo muito pessoal, portanto, para fazer da loucura o modelo de uma noção de impessoalidade que seria o trampolim para uma vigorosa inclusão da relação com o outro no campo da arte. Em contraste, o alemão tendia a considerar a condição de intrínseco isolamento como própria à loucura. Enquanto o artista, mesmo o mais solitário e amargo, manteria sempre a esperança de que um dia sua obra "viva em outras almas", nas obras dos alienados estaria ausente tal "ligação instintiva", tal "diapasão humano", salvo raras exceções (PRINZHORN, 1984, p. 375).

A "arte virgem" de Pedrosa vira pelo avesso a figura do "louco" autista, criador de uma realidade autocrática e apartado da Cultura, que interessava a artistas e críticos europeus como modelo de liberdade em 
relação aos cânones. Longe de ser uma tradução da expressão "arte bruta", cunhada por Jean Dubuffet para nomear a produção de pacientes psiquiátricos e artistas naïfs que tirariam tudo - tema, ritmo, material etc. - de si mesmos, de suas "impulsões" (DUBUFFET, 1949, s/p.) e, livres de qualquer influência cultural, encarnariam um ideal de espontaneidade e individualidade, a noção pedrosiana afirma o contrário: o "louco" seria aquele especialmente atravessado pelo outro e liberado de si, e portanto capaz de aceder à dimensão supra-individual na qual a arte se realiza como comunicação essencial entre nós.

Ora, a concepção de uma espécie de comunicação direta e essencial entre clientes e equipe do ateliê de pintura - incluindo aí, ao menos por momentos, a presença de Pedrosa e de artistas de vanguarda - era o pressuposto de base da prática de Nise da Silveira. Como uma declinação do conceito freudiano de Transferência no campo da arte, a "emoção de lidar" estava no centro da produção dos artistas do Engenho de Dentro. A problemática eu/outro era ali, neste sentido, concretamente vivenciada como fundamental para a produção artística.

Esse talvez seja o ponto de convergência fundamental, que resolve dialeticamente a contradição entre encontro entre concepções antagônicas de arte e de inconsciente de Nise da Silveira e Mário Pedrosa. De um lado, temos a crença na expressão de símbolos que neles mesmos seriam transformadores e curativos, e seu correlato desprezo pela produção não figurativa, que denotaria desorganização psíquica. De outro, a crença na arte como linguagem fundamentalmente não figurativa e por isso mesmo universal, na qual se expressa não um eu interior profundo mas sim o sujeito despersonalizado que se realiza ao tomar forma, em disseminação no mundo e em comunicação com o outro. No primeiro, temos o louco como representante privilegiado da expressão direta da "velha língua dos símbolos", e no segundo, o insano como aquele que pode mais facilmente ativar o campo da linguagem para além da mímesis e da significação, pondo em movimento e ritmo elementos significantes como a linha e a cor, e assim investindo-os de subjetividade.

No primeiro polo, temos o objetivo de penetrar no refratário mundo do esquizofrênico graças à arte; no segundo, o de ver na produção daquele que foge da norma a confirmação da "senha emotiva" que abre as portas da arte moderna. Talvez esses dois objetivos sejam mais complementares do que opostos; seja como for, eles compartilham uma atitude ética fundamental, entrecruzando os campos da clínica e da arte. E tal articulação se desdobrará, na década de 1960, como alargamento de uma 
prática artística "pós-moderna" que Pedrosa, comentando a obra de Hélio Oiticica, considerará como essencialmente ética (PEDROSA, 1966).

\section{Referências}

CORDEIRO, Waldemar. et al. Manifesto Ruptura. In Cordeiro, A. (Org.). Waldemar Cordeiro. Fantasia Exata. São Paulo: Itaú Cultural, 2014.

DUBUFFET, Jean. L'Art Brut préféré aux Arts Culturels (Catálogo da exposição realizada na Galeria René 117 Drouin, Paris), 1949. Disponível em

<https://monoskop.org/images/b/b1/Compagnie_de_I_Art_Brut_L_a rt brut_prefere aux arts_culturels_1949>. Acesso em 30 de Março de 2020

JUNG, Gustav. O Espírito na Arte e na Ciência. Petrópolis: Vozes, 1985.

KOFFKA, Kurt. Problems in the Psychology of Art. In BERNHEIMER, R.; CARPENTER, R.; KOFKA, K. \& NAHM, M. Art: A Bryn Mawr Symposium. Bryn Mawr: B. M. College, 1940.

MAVIGNIER, Almir. O Início do Ateliê de Pintura. In Imagens do Inconsciente. Mostra do Redescobrimento. São Paulo: Associacão Brasil 500 anos Artes Visuais, 2000.

MERLEAU-PONTY, Maurice. A Dúvida de Cézanne. In O Olho e o Espírito. São Paulo: Cosac Naify, 2004.

. Fenomenologia da Percepção. São Paulo: Martins Fontes, 2011.

PEDROSA, Mario. Exposição de alienados. In Correio da Manhã. Rio de Janeiro, 4 de fevereiro de 1947.

Pintores de Arte Virgem. In Correio da Manhã, Rio de Janeiro, 19 de março de 1950.

Arte Ambiental, arte pós-moderna, Helio Oiticica. Correio da Manhã, Rio de Janeiro, 26 de junho de 1966.

. Introdução. Museu de Imagens do Inconsciente. Rio de Janeiro: Funarte/Ibac, 1994. 
. Da Natureza Afetiva da Forma na Obra de Arte. In Arantes, O.

(org.)

Forma e Percepção Estética. São Paulo: EDUSP, 1995.

Arte. Ensaios: Mário Pedrosa (org. Lorenzo Mammi). São Paulo:

Cosac Naify, 2015.

PRINZHORN, Hans. Expressions de la Folie. Dessins, Peintures, Sculptures d'Asile. Paris: Gallimard, 1984.

SILVEIRA, Nise. da. 9 Artistas de Engenho de Dentro. In Ferreira Gullar. Nise da Silveira. Rio de Janeiro: 235 Relume Dumará / Rioarte, 1996.

. O Mundo das Imagens. In Imagens do Inconsciente. Mostra do Redescobrimento. São Paulo: Associacão Brasil 500 anos Artes Visuais, 2000.

. Imagens do Inconsciente. Rio de Janeiro: Alhambra, 1981.

. Entrevista condedida a Bocai, D.; Bueno, J.; Lins, J. \& Paulo, J. "Nise da Silveira, Antonin Artaud e Carl Gustav Jung" (Entrevista com Nise da Silveira). In Mello, L. C. (org.) Nise da Silveira (Encontros). Rio de Janeiro: Beco do Azougue, 2009.

Entrevista concedida a Pedro Camargo e Bernardo Horta. Do caralampismo à emoção de lidar. In Mello, L. C. (org.) Nise da Silveira (Encontros). Rio de Janeiro: Beco do Azougue, 2009.

VILLAS-BOAS, Glaucia. A Estética da Conversão: o ateliê do Engenho de Dentro e a arte concreta carioca (1946-1951). Tempo sociológico (online), vol. 20, n. 2, 2008.

WORRINGER. Wilhelm. Abstraction and Empathy. Traduzido por Michael Bullock. New York: International University Press, 1953.

\section{Notas}

1) Utilizamos aqui a versão francesa Expressions de la Folie. Dessins, Peintures, Sculptures d'Asile, op. cit. 41 A versão original tem por 
título Bildnerei des Geisteskranken. Ein Beitrag zur Psychologie und Psychopatologie der Gestaltug (Berlim/Heidelberg: Springer) Adotamos a tradução de Bildnerei, termo inabitual na língua alemã, por 'Imaginária', seguindo a proposta de Mário Pedrosa em "Forma e Personalidade" (PEDROSA, 2015, p. 160) 